\title{
Espacialidades de um novo tempo no sertão cearense: Políticas públicas e reestruturação urbana em Sobral/Ce
}

\author{
Spatiality of new time in the sertão cearense: Public Politic and Urban \\ Restructuring In the Sobral/Ce
}

\section{Juscelino Gomes Lima}

Instituto Federal de Ensino Técnico e Tecnológico do Piauí - IFPI - Altos - Piauí - Brasil

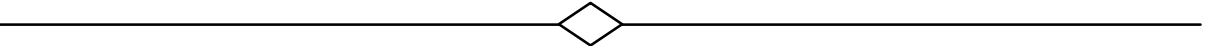

Resumo: O presente texto busca apontar a trajetória de constituição das políticas públicas e sua espacialidade, com vistas à organização espacial urbana do interior do estado do Ceará, notadamente, com reflexos sobre a reestruturação na cidade de Sobral. A visualização destas ações iniciadas ainda na década de 1970 e aprofundadas no limiar dos anos de 1990 dá luz de entendimentos sobre as dinâmicas de transformações urbanas nesta cidade em momento atual, fato que tem feito desta, em ambiente sertanejo cearense, uma urbe de representatividade e notoriedade regional para os investidores. Para o alcance deste objetivo, dialogou-se com autores referendados nas temáticas em discussão. Assim, observa-se que o dinamismo alcançado por Sobral, em "espaços secos" do Ceará perpassa além de sua remodelação territorial: também de seu conteúdo, marcado por novas condições e contradições sócio espaciais.
\end{abstract}

Palavras-chave: Sobral. Políticas públicas. Reestruturação urbana.

\begin{abstract}
This paper seeks to identify the trajectory of constitution of public policies and their spatiality, with a view to urban spatial organization in the state of Ceará, in particular, with reflections on there structuring in the city of Sobral. The visualization of these actions started in the 1970 and depthatthe (dep that the) threshold of the 1990 gives light on understanding the dynamics of urban transformations in this city in the present moment, afact that has done this in back country environment Ceará, a city of representative ness and notoriety for investors, at which your image is reworked and in the mean time, also the hinterland of urban spaces adjacente to it and influenced. To reach this objective, dialogued with authors end orsed the themes under discussion, inaddition, anexhibition of preliminar results that has been building in dissertation work that also fosters discussions that perspective. Thus, it is observed that the momentum achieved by Sobral, Ceará in dry permeates beyond its territorial remodeling: also its contents, marked by new socio-spatial conditions and contradictions.
\end{abstract}

Keywords: Sobral. Policies Public. Urban Restructuring. 


\section{Introdução}

Localizando a cidade de Sobral/CE no contexto das transformações urbanas brasileiras, particularmente, as que inserem-se no rol das denominadas cidades médias, há de se perceber que seu arranjo no momento atual é fruto de uma amalgamação de valores construídos em tempo pretérito e que acumulou condições para refletir seu presente e desenhar seu futuro.

A multiplicidade e diversidade de interesses e ações engendradas por agentes produtores do espaço permitem além de uma reestruturação nessa cidade, também um influenciar nesse sentido sobre cidades menores em seu em torno de localização. 0 conjunto de dinâmicas permitidas local e regionalmente obedece ao comando de um sistema de ações que define uma lógica, uma dada racionalidade, ou seja, aquela da vida social que o anima; e de um sistema de objetos que, por sua vez, define a materialidade territorial dessa dinâmica (SANTOS, 1994).

Nesse direcionamento, a urbe sobralense apresenta-se transformada dinamicamente pelo viés capital imobiliário e como tantas outras de seu leque classificatório e dentro de seu quadro regional, vêm desempenhando "um papel político, econômico e social de crescimento para toda uma região" (SPOSITO,2009,p.19), fato que tem redimensionado conseqüências sobre sua forma, conteúdo e organização espacial. Estas condições marcam a espacialidades de um novo tempo sobre os sertões da porção norte do estado do Ceará, via constituição e aplicação de políticas públicas ${ }^{1}$, em especial destaque, sobre a referida cidade.

O desempenho em tela tem permitido uma forte articulação socioespacial (entre Sobral e trinta e nove cidades sob seu raio de influência, conforme se verá na fig. 02 em páginas adiante), notadamente a que faz-se mediada pelas atividades de comércio e serviços. Esse fato tem colaborado para uma

\footnotetext{
1 Elenca-se ai um conjunto infraestrutural a exemplo de abertura e renovação de vias de circulação, ampliação deestruturas energéticas, políticas de incentivos fiscais, renovação estrutural das cidades para recebimento de investidores, etc.
}

reinvenção imagética ${ }^{2}$ dos espaços sertanejos no estado do Ceará. Saltam aos olhos, os resultados engendrados via políticas públicas com vistas à renovação material do espaço e o alcance (mesmo que haja prioridade dos objetivos particulares em detrimento dos de ordem coletiva na reorganização espacial) permitido por tais políticas, uma vez que estas vêm se fortalecendo nas últimas décadas motivadas entre outras, "pela demanda de reestruturação do espaço e o reordenamento do território em face à atual fragmentação das cidades" (MELLO-THÉRY,2011,p.12).

O presente texto busca apontar a trajetória de constituição das políticas públicas e sua espacialidade, com vistas à organização espacial urbana do interior do estado do Ceará, notadamente, com reflexos sobre a reestruturação na cidade de Sobral. Assim, o artigo é constituído de três seções, onde na primeira é discutido as fases de formação e organização sócio territorial do Ceará e seus rebatimentos sobre a composição da cidade de Sobral.

Para a segunda seção é apontado as diferentes condições e atuações das políticas públicas sobre espaços interiores do estado do Ceará, com enfoque sobre a cidade de Sobral e como estas, os diferentes desdobramentos não apenas local, mas regional, considerando o alcance permitido por esta cidade sertaneja. No terceiro e último momento desta discussão faz-se um fechamento das idéias discutidas e objetivadas.

\section{Sobral: bases de sua configuração territorial}

Entender os processos de constituição do território de Sobral significa em sua concretude remontar à ocupação do espaço cearense que se constituíra sob os auspícios dos processos de

\footnotetext{
2 Estas novas condições imagéticas são permitidas pela pujança e notoriedade que os espaços urbanos do sertão atravessam (no caso em questão, Sobral ao enxergar, por exemplo, a presença de novos equipamentos de consumo shopping, boutiques, antes exclusivos da capital do estado e ou de importantes cidades), pois por muito tempo a concepção que se constituira no imaginário da sociedade do Brasil sobre este grande espaço do Nordeste brasileiro sempre fora de atrasos e péssimas condições sociais.
} 
colonização, materializados sob diversas fases, atores e circunstâncias, engendradas no sentido do deslocamento interior/litoral e vice-versa. Dito isso, entende-se ser necessário antes de tudo fixar um olhar cartográfico de localização de Sobral, dentro do quadrante territorial do estado do Ceará, conforme se vê na fig. 1 abaixo, já que este fato permite enxergar que seu posicionamento é algo estratégico e que ganha dimensão a partir de sua incursão de formação e organização socioterritorial.

Fig.1: Localização do Municipio de Sobral/CE.

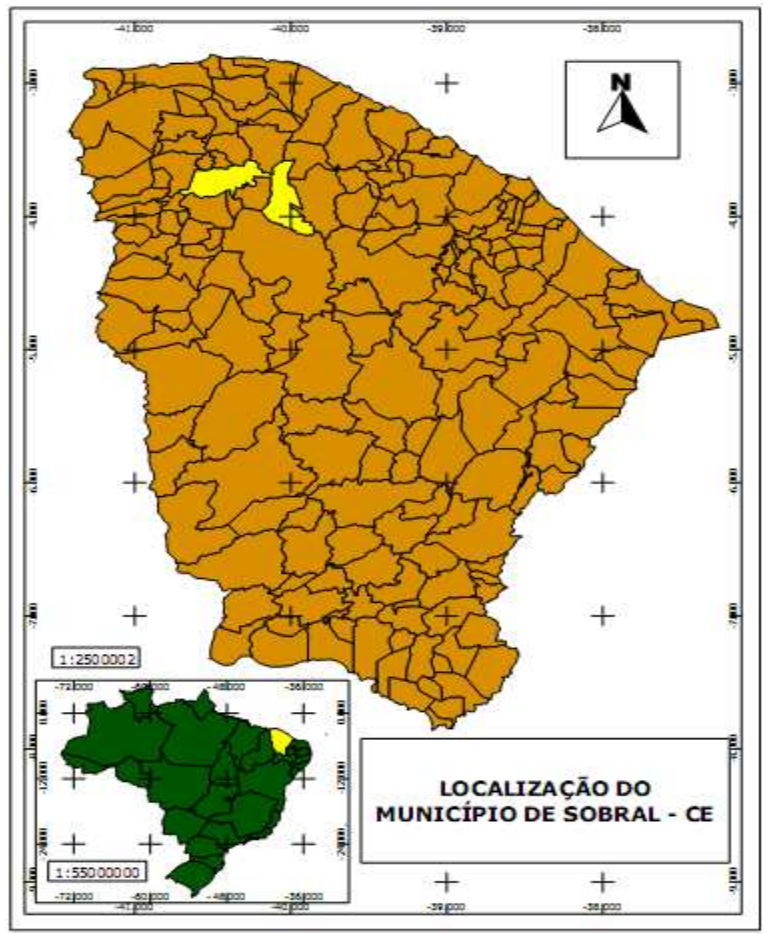

Fonte: O autor, 2013.

Como ponto de partida, a materialização neste território convoca mesmo que de forma preliminar uma discussão conceitual acerca dos Espaços Geográficos, momento que entre tantas conceituações encontradas nas diferentes literaturas do campo geográfico e ou das Ciências Sociais, optamos trabalhar uma celebre dita por SANTOS (1982, p.30), expondo que "o espaço é uma acumulação desigual de tempos".

Vemos nessa perspectiva, a ideia de que os tempos se revestem de ações e condições que ajudam a fomentar conteúdo, valor e forma aos espaços em processo de dinamização. $\mathrm{Na}$ fomentação em tela, encontram-se diversos sujeitos, com diferentes ações e objetivos no processo de organização espacial, fato que caracteriza e marca a "convergência dos momentos" (SANTOS, 2000, p. 43).

Considerando esse entendimento, enxergamos que é na historicidade dos deslocamentos sazonais feitas aos espaços interiores do território do Ceará, que fez-se erguer um principiado de economia da então capitania do Ceará, resultado das ações dos desbravadores do sertão que com a implantação das fazendas de gado, criaram o embrião das charqueadas que logo tornara este território de expansão colonial, como um dos maiores produtores do Brasil colônia, em fins do século XVIII, "fato que dá vida e notoriedade a algumas conhecidas cidades do interior, a exemplo de Aracati, Icó, Sobral, que mais tarde fora continuada com a fase produtiva do algodão" (LIMA, 2011).

As ações sertanistas de desbravamento confeccionaram uma teia de relações espaciais, entre os diferentes espaços de colonização no território sertanejo cearense que foram interconectados pelo desenho de estradas por onde vagaram longínquos e muitas vezes perdidos viajantes e comerciantes. Com estes, as longas travessias nos sertões do Ceará, movimentaram e deram escopo de conteúdo à Sobral, espaço de onde "os primeiros povoadores foram ocupando as margens dos Rios Acaraú, Coreaú, Aracatiaçu, Aracatimirim e de seus principais afluentes, cujas áreas configuram a depressão sertaneja onde se situa Sobral" (COELHO, 2007, p. 303).

Nesse direcionamento, edificam-se os rumos de ocupação das terras da futura cidade de Sobral. A tessitura da teia de interconexão já citada anteriormente responde nesse encaminhamento, a partir da criação de elos de sociabilidades comerciais, entroncamento de diferentes valores sociais, ambos margeados pela presença e importância do Rio Acaraú, que pelos idos do:

século XVIII marcou o processo inicial de ocupação das terras que deram origem a Sobral, desde o povoado da Caiçara, a partir da fazenda de gado de mesmo nome, localizada à margem esquerda do rio Acaraú, 
em plena depressão sertaneja, no sopé da serra da Meruoca (ponto de referência que orientava os viajantes da ribeira do rio Acaraú) (AGUIAR JR., 2005, p. 26).

Vê-se assim, que Sobral emerge no contexto do semiárido nordestino do Ceará com um diferencial de muitos outros núcleos que se gestaram pelo viés e ditames das incursões colonialistas do século citado, que é justamente o fato de sua presença ser edificada entre o rio Acaraú e a formação geológica ${ }^{3}$ da Serra da Meruoca de grande aproveitamento socioeconômico local. Assim, entre outras características e aproveitamentos, a formação em destaque é conhecida por possuir uma "presença de alvéolos entre os níveis elevados propiciando melhores condições edáficas em relevos planos e favorecendo maior aproveitamento agrícola" (LIMA, 1999, p. 45).

O fato de se localizar entre dois elementos geoambientais distintos reforçou o valor estratégico de "gestação" e desenvolvimento da fazenda Caiçara, espaço embrionário da urbe sobralense e que apresentou grande desenvoltura enquanto núcleo de vivências sociais coletivas até 1773. É desta data em diante que se inaugura a criação da Vila Distinta e Real de Sobral que já aparecia naquele momento como um espaço de relevância social no sertão cearense.

A importância dita foi marcada pelas sociabilidades dos encontros/atividades religiosas, que congratulavam um numero crescente de pessoas, local e adjacente a recém vila, possibilitando, além disso, a consagração da mesma como um "centro distribuidor das mercadorias para um vasto sertão agropastoril" (SOUZA, 2007, p.20).

Mesmo apresentando essa excepcionalidade já à época, a Vila de Sobral estava presa a mecanismos de controle político. Desse fato, seu conteúdo territorial, assim como também o do Ceará, estavamsubordinados à Província da Bahia, que em seguida fora repassada a de Pernambuco, em fins do

\footnotetext{
Segundo revela Souza (1988), em trabalho intitulado "Contribuição ao estudo das unidades morfoestruturais do Estado do Ceará", a Serra da Meruoca está inserida no Domínio dos Escudos e Maciços Antigos compostos de Litotipos datados do Pré Cambriano.
}

séc. XVIII, momento que ainda conservou e intensificou as várias relações de comércio e nesse ínterim, uma confecção social além de ampliada, diversificada, particularmente, quando o:

Ceará conseguiu sua emancipação política em 1821, reflexo da organização administrativa oriunda da evolução econômica e social que já se estabelecera. Nasce Fortaleza, a primeira cidade em 1823. Em seguida, antigas vilas se tornam cidades e Sobral foi a primeira delas, pela lei $n^{\circ} 299$, de 12 de janeiro de 1841, e, nos três anos seguintes, Icó, Aracati e Crato (HOLANDA, 2010, p. 78).

O amadurecimento e mudança de fase (de vila a cidade) reforçam a ideia finalizada no parágrafo anterior. A partir desse momento foi possível visualizar o desenho de uma importante cidade sertaneja, fruto de sua dinamicidade econômica que fora paulatinamente intensificada, que a exemplo também da cidade de Aracati, que se localiza em ambiente marítimo leste do Ceará, ambas cidades agora, a partir de "suas funções comerciais, exportam a carne de charque diretamente para a Bahia e Pernambuco" (IDEM, 2010, p. 78).

As charqueadas esboçaram a tentativa de integração não só econômica e social, mas também espacial entre os diferentes lócus de caráter urbano do Ceará. Isso foi permitido pela prática do gado abatido e transformado em carne salgada conhecida como a Carne do Ceará. Esse acontecimento incrementou a ciranda de desenvolvimento de núcleos urbanos nordestinos e cearense, particularmente, sob a figura da mão de obra escrava, retroalimentando o investimento de senhores de fazendas, como também dando tons de cores à paisagem seca das estradas do sertão por onde vagavam um grande número de grupos de boiadas.

Transformações mais amplas sobre o Ceará e Sobral foram permitidas ainda no segundo quartel do séc. XIX, quando da Guerra da Secessão nos E.U.A, que obrigara este país, até então, o maior produtor e exportador do mundo à época de algodão, deixar o mercado vazio. Nesse ínterim, o Nordeste, particularmente, o Ceará aproveitou a lacuna de 
produção, possibilitando a esta parte do Brasil ingressar "no cenário exportador brasileiro, ao mesmo tempo em que em que adquire maior independência em relação ao controle das atividades econômicas" (AMORA; COSTA, 2007, p. 354).

O ingresso do Ceará na dianteira da produtividade e competitividade internacional via produção algodoeira lhe rendeu muitos benefícios capitais, mas principalmente uma "maior necessidade de investimentos em pontes e estradas de ferro, e a ocorrência de drenagem de riquezas para as cidades que desenvolvem, sobretudo, o comércio" (IDEM, 2007, p. 354). Nesse direcionamento, o comércio fora incrementado, a partir do fortalecimento da aliança entre a produção de gado que já se manifestava como importante e a emergência do algodão como elemento diferenciador do contexto produtivo até então.

Essa dinâmica não estaria completa se não apontássemos o despontar de um inicial processo de tecnificação do espaço na cidade de Sobral. Este momento contrastou com períodos anteriores até então marcado pela produtividade agropastoril e extrativista e que chegou produzindo a noção de um novo tempo, chegando a "desmantelar a harmonia do conjunto, determinar a ruptura do tempo e a permissão de entrada em um novo período"(SANTOS \& SILVEIRA, 2006, p. 24).

A partir desta reflexão destacamos a chegada da Companhia de Fiação e Tecidos Ernesto Deocleciano $^{4}$, bem como da CIDAO $^{5}$ - Companhia Industrial de Algodão e Óleo e muitas outras, das quais estavam ligadas ao setor extrativista. Estas se somaram à chegada do transporte ferroviário proporcionando uma verdadeira remodelação do espaço geográfico sobralense e conexão com outras partes do território cearense e nordestino. Era o nome de Sobral no limiar do séc. XX, projetando novos valores territoriais no sertão do Ceará e amarrando

\footnotetext{
4 Fora fundada por dois sócios: Ernesto Deocleciano de Albuquerque, beneficiador de algodão do Ceará e Cândido José Ribeiro, industrial do ramo Têxtil no Maranhão, em 1894.

5 Teve suas funções iniciadas em 1921 e encerradas em 1970, tendo como cidade piloto de atuação, a cidade de Iguatú - CE e com localização posteriormente de unidade de produção e atuação para cidade de Sobral.
}

novas condições de investimentos à remodelação do Nordeste seco.

Nesse contexto, o espaço geográfico sobralense já apresentava uma boa dose de condição material e financerização de seu território, considerando outros espaços do Nordeste seco que não tivera as mesmas oportunidades de mudanças possibilitadas pelos agentes e movimentos de investimentos. Nesse ponto, corrobora-se a nosso pensamento o de que o:

espaço geográfico deve ser concebido como um produto histórico e social das relações que se estabelecem entre a sociedade e o meio circundante. Essas relações são, antes de tudo, relações de trabalho dentro do processo produtivo geral da sociedade (CARLOS, 1999, p.15)

Pensando assim, as relações estabelecidas e aqui dialogadas, enraizaram desde cedo à Sobral, condições para uma materialização espacial que condicionou além de um revigoramento produtivo, também um projetar urbano de monta, construindo condições impares a um contexto social que desvencilhou desde cedo as amarguras do ser e viver no sertão cearense.

Assim, o desenrolar do século XX para Sobral mostra claramente sua posição adquirida em séculos anteriores. A função comercial prevalece. Seu raio de influência a outros municípios é alargado. Sua sociedade é modelada a partir de uma nova forma de materialização lógica do capital. Esta nova lógica é viabilizada pelos consumos de produtos e serviços que chegam de fora, fato que encaminha a cidade nas primeiras décadas do século em destaque a uma afirmação de "empório de produtos provenientes do sul do Brasil e da Europa, desenvolvendo-se como entreposto comercial com irradiação para Fortaleza e outras cidades do Ceará, Piauí e Maranhão" (COELHO, 2007, p. 306).

É evidente que diante das circunstâncias narradas, Sobral felicitou-se em aproveitar as condições edificadas em seu processo histórico de formação. Estas foram marcadas e conhecidas não só na peleja da desbravura da paisagem seca, mas principalmente pela conjectura de ações e comandos de investimentos capitais e ações políticas nela 
aportados, desenhando novas condições de ser e estar no sertão.

\section{Políticas públicas e produção do espaço urbano na cidade de sobral: trajetórias e novas funcionalidades no sertão norte cearense}

As condições sócio históricas orquestradas em espaços interiores do Ceará, notadamente, em Sobral, pelos idos da colonização e começo do século XX nos apresenta elementos de um quebra cabeça, com peças perfeitamente encaixantes que ligam-se para o além de seus formatos - o do conteúdo. Nesse direcionamento, a formação e consolidação da urbe sobralense e de tantas outras do interior do Nordeste do Brasil, considerando os similares processos de colonização são respaldadas pela ideia de que as cidades são "a expressão concreta de processos sociais na forma de um ambiente físico" (Harvey, 1972 apud CORRÊA, 2010).

Raciocinando nesse direcionamento, então há de se conceber de forma sintética que a cidade é um reflexo da sociedade. A cidade aqui objetivada e que vai de encontro com este entendimento são as denominadas de porte médio. Contudo, quando lançamos um olhar sobre esta terminologia, veremos que a mesma estanca de relance para qualquer desapercebido, no critério de grandeza. Quando falamos em cidades grandes, medias ou pequenas, nossa memória recorre a seu tamanho físico e como tal, abarcando diferentes possibilidades de sua exponencialidade urbana (tamanho populacional, produtividade, influências, etc.).

A despeito destas terminologias que elucidam vetor de grandeza, muito já se tem refletido, particularmente, quando se trata das cidades médias, momento dialético entre diferentes estudos e áreas onde parece ausentar-se um consenso no uso e validade deste termo, uma vez que:

existem vários autores que tratam da questão das cidades médias e, através de seus estudos, pode-se notar que é difícil chegar a uma definição. No entanto, se for considerado apenas o fator populacional, pode-se destacar algumas posições. $\mathrm{Na}$ visão da $\mathrm{CEPAL}^{6}$ cidade média é considerada como sendo aquela cidade que apresenta uma população entre 50 mil e 1 milhão de habitantes; já para Soares $(2005)^{7}$, as cidades médias são representadas por um tamanho populacional entre 200 mil a 1 milhão de habitantes; por sua vez Maricato $(2001)^{8}$ coloca entre os limites de 100 e 500 mil habitantes [...] (STAMM et al, 2010, p. 73).

Assim, adotaremos o critério demográfico do IBGE que afirma serem estas cidades, as que se enquadram na totalidade de habitantes que vão de 100 a 500 mil habitantes (cidades de porte médio), onde a cidade de Sobral, pela última averiguação do Censo deste órgão em 2010, registrou-se 166.310 habitantes. Associado a este critério, acreditamos também ser necessário uma:

preocupação em considerar outros elementos e, a nosso ver, a definição de cidade média deve ter por base além do critério demográfico, as funções urbanas das cidades relacionadas, sobretudo, os níveis de consumo e o comando da produção regional nos seus aspectos técnicos (FREIRE, 2011, p.37).

Justamente ao considerar estes outros elementos é que percebemos Sobral e tantas outras de seu leque classificatório que as mesmas, no transcorrer do século XX, são fruto das diferentes políticas de reordenamento territorial acontecidas em diferentes governos, ou melhor, dizendo, diferentes períodos desenvolvimentistas ${ }^{9}$. Os períodos citados, inseridos no contexto nacional de transformações socioespaciais, via industrialização, costuraram e processaram-se em três fases distintas, a saber:

\footnotetext{
${ }^{6}$ Ver CEPAL - Comissão Econômica para América Latina e o Caribe. El rostro de La urbanizaciónen América Latina y el Caribe. Serviço de informação da CEPAL - Comunicado de imprensa. In: Conferencia regional sobre el programa de Hábitat. Chile, 2000. Disponível em: <http://www.eclac.cl/cgibin/getProd.asp?xml=/prensa/noticias/co municados/1/5041/P5041.xml\&xsl=/prensa/tpl/p6f.xsl>

${ }^{7}$ Ver SOARES, Paulo Roberto Rodrigues. Cidades médias e aglomerações urbanas: a nova organização do espaço regional no Sul do Brasil. In: I Simpósio Internacional Cidades Médias: dinâmicas econômicas e produção do espaço urbano. Anais. Presidente Prudente: Unesp, 2005.

${ }^{8}$ Ver MARICATO, Ermínia. Brasil, cidades: alternativas para a crise urbana. Petrópolis, RJ: Vozes, 2001.

9 Este termo tem forte ligação e inserção do Ceará, via investimentos e infraestruturas, em diferentes governos, a partir de 1960, encaixada em diferentes altos e baixos momentos de desenvolvimento econômico e social do Brasil.
} 
primeira engloba o início do século $X X$ até a criação da Superintendência de Desenvolvimento do Nordeste - SUDENE e é resultante do fortalecimento da proto-indústria na segunda metade do século XIX. A segunda é demarcada pelo intervencionismo institucional da SUDENE e demais órgãos e pelos projetos de integração nacional e industrialização. $E$, por último, responde o período pós-SUDENE, marcado pela desaceleração das políticas industriais experimentada nas últimas duas décadas (ALMEIDA, 2012, p.10).

De todo modo e por diferentes décadas do século $X X$, os gestores locais, se apresentaram como principais articuladores das políticas industriais e desenvolvimentistas. É a partir destas, que dão-se os alicerces de crescimento e conteudização das cidades médias sertanejas, em particular relevo, Sobral, no Ceará. Nesse direcionamento, diferentes ações marcaram-se como esforço da extensão de uma política nacional, onde entre a representação estatal maior e a menor o:

Nordeste ensaiou um grande surto de desenvolvimento via indução industrial, transformando a região numa produtora de bens intermediários - Surgiram pólos produtivos especializados como 0 petroquímico e cloroquímico, na Bahia, o metal-mecânico, em Pernambuco, o complexo de salgema e sucro-alcooleiro, em Alagoas, o complexo minero metalúrgico, no Maranhão, o pólo têxtil e de confecções de Fortaleza e o agroindustrial no perímetro irrigado do Médio São Francisco, dentre outros (Op.Cit. 2012, p.11).

Visualiza-se ai, o esforço do Estado na confecção de uma das mais ousadas e dialéticas formas de políticas públicas para "salvar" o Nordeste, de suas lastimações e atrasos. A forçosa tentativa de integrar o Brasil e seus "recortes" territoriais na Divisão Internacional e Territorial do Trabalho, considerando a dinâmica capitalista no mundo pós Segunda Guerra, fez "os investidores, com o beneplácito do Estado, aumentam a articulação indústria/agricultura, visando à integração de mercados. Onde o capital financeiro nacional e internacional se fez ampliar especulativamente e produtivamente" (HOLANDA, 2007, p.94).

As ações e projeções de investimentos e orientações para tal no Nordeste via SUDENE, contribuíram de forma exemplar para uma reconfiguração espacial do Nordeste brasileiro e obviamente, de cidades interiores do estado do Ceará, a exemplo de Sobral que fora mediada pelo cortejo da implantação dos "Fixos e Fluxos", tal qual aponta Santos (1996, p. 141).

Para a consecução da implantação em destaque uma sequência de governos que se deu do início de 1960 até a primeira metade de 1980, denominado de período coronelista ${ }^{10}$ muito contribuiu ao quadro econômico e organizativo do ponto de vista espacial do Ceará. Virgilio Távora, por exemplo, ao governar o Ceará por duas vezes, possibilitou ações materiais sobre 0 estado, repercutindo nos deslocamentos dos investimentos às cidades do interior, refletindo-se em Sobral, promovendo "a construção de rodovias ligando cidadesdo interior, do Baixo Jaguaribe que, algumas décadas mais tarde, tornam-seum "novo espaço da produção globalizada" no Estado do Ceará e atraigrandes grupos industriais como a Grendene" (ARAUJO, 2007, p. 101).

Lembrando então da primeira fase da industrialização do Ceará, notadamente, a que recaiu sobre a cidade de Sobral ainda em fins do séc. XIX, é perceptível o alongamento deste processo no desenrolar do segundo quartel do séc. $X X$, onde a presença dos "fixos e fluxos" delimitam os espaços seletivos do Ceará sertanejo, como Sobrale outras numeradas cidades, a exemplo de Juazeiro do Norte, Crato, Iguatu, etc. e que foram envoltos por políticas públicas de reordenamento produtivo e econômicos que suscitaram convites a investidores como novos lócus de reprodução capital, sinônimo de desenvolvimento territorial ${ }^{11}$.

10 Este período corresponde ao momento das vivências políticas no Brasil, marcada pelos ditames dos governos militares e que no caso do Ceará, movimentou-se pela troca de poder entre os governadores Virgílio de Morais Fernandes Távora (1963-1966); Plácido Aderaldo Castelo (1966-1971); César Cals de Oliveira Filho (1971-1975); José Adauto Bezerra (1975-1978); Virgílio de Morais Fernandes Távora (1978-1982) e Luiz de Gonzaga Fonseca Mota (1983-1987).

11 Faz-se importante e necessário frisar que o dinamismo econômico, logo, urbano destas cidades interiores do Ceará, a partir das ações da SUDENE, a partir de 1960, notadamente para Sobral, é diferente do desenvolvimento alcançado, dos anos de 1990 em diante, haja vista, os diferentes atores e circunstâncias engendrados. 
As ações de investimento de reorganização sócioprodutivas no Ceará, destacadamente, em suas diferentes cidades, a exemplo de nosso objeto de discussão que é Sobral não se encerraram com este governante, mas abriram um leque de possibilidades de ações políticas para continuidade de tal desenvoltura, a partir da década de 1970 em diante.

É considerando o recorte temporal em diante e o intuito de visualizar como cidades a exemplo de Sobral e outras de porte médio ganharam dimensão ímpar nos espaços sertanejos cearenses, via investimentos produtivos que passaremos agora a mostrar resumidamente na tabela 01 a seguir as principais ações/estratégias políticas adotadas sinalizando mobilidade para tal desenvoltura e que são apontadas de forma exemplar por HOLANDA (2010).

Tabela 01 - Políticas de Planejamento Estatal no Ceará

\begin{tabular}{|c|c|c|c|}
\hline $\begin{array}{c}\text { Criação/ano de } \\
\text { implantação }\end{array}$ & Objetivos & Ações & Espaçoabarcado \\
\hline CODEC $^{\prime}$ & $\begin{array}{l}\text { Criação de } \\
\text { Infraestruturas, } \\
\text { de zonas } \\
\text { indústrias de } \\
\text { análise oportunidades } \\
\text { oporias, etc. } \\
\text { industriais, }\end{array}$ & $\begin{array}{l}\text { Assessorava os } \\
\text { empresários } \\
\text { como forma de } \\
\text { obter recursos } \\
\text { financeiros junto } \\
\text { a órgãos } \\
\text { competentes. }\end{array}$ & $\begin{array}{l}\text { Várias cidades } \\
\text { em processo de } \\
\text { dinamização } \\
\text { econômico } \\
\text { territorial } \\
\text { Estado, no } \\
\text { elas, Sobral. }\end{array}$ \\
\hline $\mathrm{ASIMOV} / \mathrm{PUDINE}^{1}$ & $\begin{array}{l}\text { Desenvolvimento } \\
\text { de atividades } \\
\text { industriais de } \\
\text { produtos locais. }\end{array}$ & $\begin{array}{l}\text { Apoio ao ramo } \\
\text { de } \\
\text { beneficiamento } \\
\text { de produtos } \\
\text { locais (castanha } \\
\text { de caju, leite, } \\
\text { etc.). }\end{array}$ & Crato/Sobral \\
\hline $\mathrm{PLAIG}^{1}$ & $\begin{array}{l}\text { Elaboração de } \\
\text { estudos que } \\
\text { diagnosticasse } \\
\text { as } \\
\text { potencialidades } \\
\text { socioeconômicas } \\
\text { regionais do } \\
\text { Ceará }\end{array}$ & $\begin{array}{l}\text { Modernização } \\
\text { das rodovias; } \\
\text { Elenca-se por } \\
\text { meio de } \\
\text { diagnósticos } \\
\text { áreas } \\
\text { polarizadoras no } \\
\text { estado. }\end{array}$ & $\begin{array}{l}\text { Fortaleza; } \\
\text { Sobral; } \\
\text { Crato-Juazeiro do } \\
\text { Norte e; } \\
\text { lguatu, com mais } \\
\text { quatro áreas } \\
\text { polarizadoras e } \\
\text { doze centros } \\
\text { regionais, com } \\
\text { base em estudos } \\
\text { feitos pelo IBGE. }\end{array}$ \\
\hline PLANDECE $^{1}$ & $\begin{array}{lr}\text { Dinamizar } & \text { os } \\
\text { centros urbanos } \\
\text { com populações } \\
\text { superiores a } \\
15.000 \\
\text { habitantes. } \\
\end{array}$ & $\begin{array}{l}\text { Diversas ações } \\
\text { com vistas o } \\
\text { desenvolvimento } \\
\text { regional. }\end{array}$ & $\begin{array}{l}\text { Na fase } 1, \\
\text { elencou-se } \\
\text { Fortaleza, Crato- } \\
\text { Juazeiro } \\
\text { Sobral. }\end{array}$ \\
\hline PLAMEG $^{\top}$ & $\begin{array}{l}\text { Continuidade da } \\
\text { política anterior } \\
\text { com adaptações } \\
\text { e visões de } \\
\text { alcance. }\end{array}$ & $\begin{array}{l}\text { Continuidade da } \\
\text { política anterior } \\
\text { com adaptações } \\
\text { e visões de } \\
\text { alcance. }\end{array}$ & 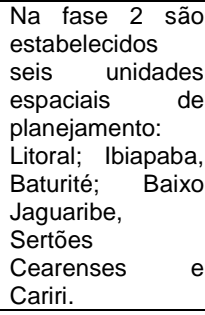 \\
\hline
\end{tabular}

Fonte: HOLANDA (2010). (Com adaptações).
Vê-se ai como importante e estratégico foi a atuação estatal junto aos processos de reordenamentos produtivos e a emergência de novos espaços de representação produtivo/capital, não só glorificando a capital Fortaleza, como líder do "corpo" organizativo e administrativo do Ceará, mas de cidades em ambientes sertanejos que racionalmente souberam receber os investidores/investimentos, preenchendo-se de novos conteúdos e valores, tal qual se postam no momento atual.

É importante lembrar que associado aos fixos e fluxos que passam a "correr" aos espaços interiores do Ceará, a partir de 1970 em diante, os diferentes governos que se intercalaram no jogo político, notabilizaram-se também pela prática da política dos incentivos fiscais. Esta prática energizou as movimentações de investimentos em parques industriais, direcionados primeiramente à Região Metropolitana de Fortaleza - RMF, mas em seguida, direcionou-se às cidades do interior, momento que exigiu destas uma tessitura espacial organizada para o recebimento dos circuitos de investimentos materiais ancorados na presença imaterial do território investido.

$\mathrm{Na}$ segunda metade da década de 1980 em diante, o Ceará assistiu ao fim da era dos ditos governadores coronelistas e a diminuição do poder das famílias oligárquicas até então operantes no seio social e econômico cearense e viu-se mergulhado na fase de governança empresarial, marcando a era do "Governo das Mudanças ${ }^{12 ", ~ q u e ~ r e u n i a ~ u m ~ e l e n c o ~}$ patrimonial de novos políticos que ventilaram novos pensamentos e virtudes ao Ceará, marcados pelas:

propostas de modernização do Estado em todas as esferas, indo ao encontro do grupo de investidores emergentes que passam a atuar no Nordeste graças ao avanço do meio técnico-cientifico-informacional, ocorrendo o reforço da inserção do lugar/região ao mundo contemporâneo, por meio da política neoliberal - flexibilidade, competitividade, privatização, modernização, descentralização (HOLANDA, 2010, p. 87)

12 Encabeçado por Tasso Ribeiro Jereissati, este governo é uma sequencia de ações políticas no Ceará e que objetivou entre outros a ruptura com o clientelismo e assistencialismos propalados pelos governos coronelistas e influenciado pelas fortes famílias de conteúdo oligárquico. 
A defesa da economia de mercado e a lógica da propriedade privada de produção dentro da perspectiva modernizante elaborada pelos discursos e ações modernizadoras vieram emoldurar um novo tempo, uma nova era, uma nova base de ser e estar do Ceará frente à conjuntura mundial que arquitetava os ditames da economia mundial pré década de 1990.

Dar entrada do Ceará nessa nova compostura desenvolvimentista requereu por parte do governador Tasso Jereissati planejamentos. E uma dos principais é via regionalização do estado, como forma de descentralização de novas oportunidades de gerenciamento e conhecimento de potencialidades de investimentos, tal qual a elaborada pelo Instituto de Planejamento do Ceará - IPLANCE, no momento da execução do I Plano das Mudanças, de 1987-1991 e que adotou como critérios condicionadores: contingentes populacionais, sistemas viários, atividades econômicas, etc.

Como resultado da incursão de gerenciamento regional, obteve-se 20 Regiões Geográficas Administrativas - RG, que incluía o reconhecimento e destaque de sete Áreas de Desenvolvimento Regional - ADR's: Especial, Litoral, Vale do Jaguaribe, Cariri, Sertão dos Inhamuns, Sertão Central e Sobral/lbiapaba. Esses recortes costuraram possibilidades intercâmbios, a partir de suas potencialidades e investimentos diferenciados e ampliados em governos seguintes.

Destes investimentos e escolhas da espacialização da produção no estado, destacadamente, as localizadas fora da Região Metropolitana de Fortaleza, denominada de ADR Especial, nos anos de 1990, viu-se que a de Sobral ADR Sobral/lbiapaba era:

composta de 20 municípios e se apresenta bastante diversificada no ramo industrial, por envolver municípios de aspectos econômicos, sociais, políticos e naturais distintos, havendo um predomínio de produtos alimentares, vestuários, calçados e artefatos de tecidos, com destaque para o setor calçadista e mais recentemente, imobiliário e de artefatos da construção civil, respondendo ai pela dinâmica espacial de maior uso e necessária para o desenvolvimento regional norte (IDEM, 2010, p. 89 - Grifo nosso).

Com efeito, os anos finais de 1990 e, notadamente, primeiras décadas que compõem o séc. XXI marcam sobre a cidade de Sobral uma atmosfera de transformações que resultam das movimentações políticas e de investimentos, fruto de tempos e condições anteriores já apontadas. As citadas movimentações, entremeadas nos processos de reorganização espacial no Ceará possibilitam mais que um rearranjo, uma espacialização dos eventos econômicos que deram vida e notoriedade a vários centros urbanos fora da Região Metropolitana de Fortaleza - RMF. Essa espacialização fora importante, pois além de doar autonomia fora dos quadrantes de influência da capital, estimulou o desenvolvimento e apêndices comerciais e produtivos, incrementando valores e resignificando o sentido de viver e investir no sertão do estado cearense.

Sobral nesse contexto é abarcado por diversos equipamentos comerciais e de serviços até então exclusivos da/na capital, influenciando gostos, decisões de compra e a definição de consumo que se heterogenizam pelo fato de a massa populacional para tal ter origem diversas, advindo daí, costumes e condições financeiras de acesso desigual que marcam os cenários dos PIB's e com este a ciranda de desenvolvimento que se edifica.

Encabeça-se assim, mediante as ações elencadas, um novo mundo urbano no sertão do Ceará. É evidente, que nem todos os recortes municipais sertanejos do estado se beneficiaram destes eventos de interesse capital, uma vez que o foco e direcionamento de investimentos nos diferentes momentos narrados corroboram com a ideia da arquitetação histórica dos Espaços Luminosos e Espaços Opacos (SANTOS, 1994, p. 29).

Dentro ainda desse contexto de pensamento e dos efeitos gerados pela propagação das políticas públicas que engendraram mudanças promissoras em cidades sertanejas cearenses, notadamente, sobre a cidade de Sobral é importante lembrar que 
tais ações políticas, via SUDENE, são diferente das que se permitiram pelos idos dos anos de $1990 \mathrm{em}$ diante. Esse fato merece evidência, uma vez que os diferentes contextos e condições em destaque não apenas deram bases de refuncionalização a esta cidade, mas principalmente, a outros espaços urbanos de base territorial sertanejo do Ceará.

Somado à desenvoltura oportunizada a Sobral, houvera também um reordenamento territorial, no sentido da ampliação de sua influência regional, possibilitando à mesma um comando territorial de 39 cidades (conforme se vê na fig. 02 abaixo), permitido nesse ínterim, uma reorganização infraestrutural antes não vislumbrados em espaços sertanejos do Ceará, fato que alimenta um crescimento e desenvolvimento em conjunto de várias cidades e dá autonomias às mesmas que antes eram "reféns" do comando central da capital Fortaleza.

Fig.2: Município de Sobral e sua área de influência

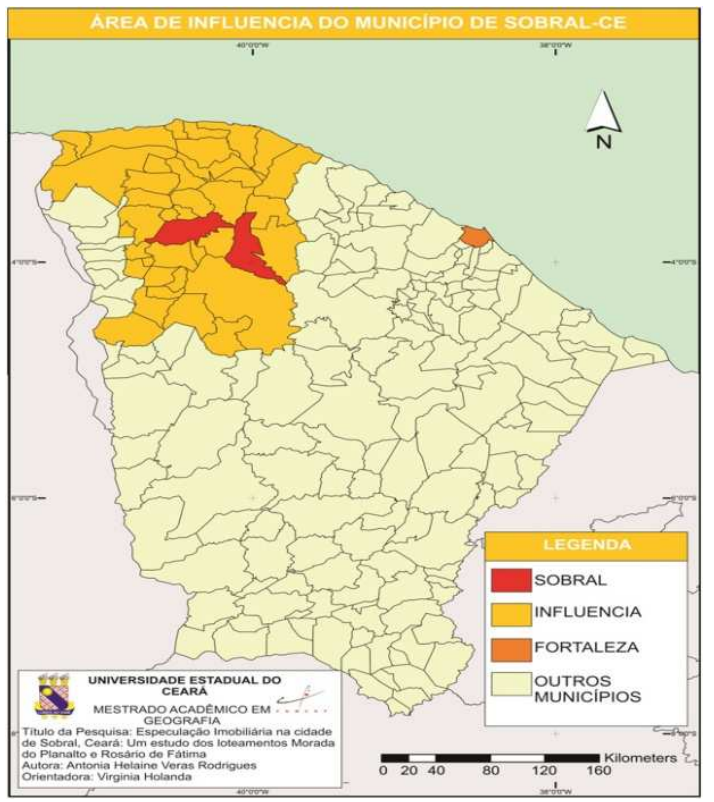

Fonte: RODRIGUES; HOLANDA, 2012.

É perceptível pela narrativa construída que as cidades sertanejas do Ceará, considerando sua continuidade histórica de organização material e técnica, acumuladas através dos tempos, foram concebidas (apesar de tardias) como aptas aos investimentos, momento que instiga-nos a lembrar a ideia outrora exposta por SANTOS (op. cit, 1994), ao enunciar a noção existencial de espaços que são iluminados pela presença dos equipamentos e condições concebidas por sujeitos capitais, para dilatação dos seus objetivados lucros, determinando assim, ou o seu sucesso (territórios luminosos) ou o seu fracasso (territórios opacos), fato que desemboca na capacidade (ou não) da/na confecção de dinâmicas urbanas regionais.

\section{Considerações finais}

Considerando os diferentes processos e condições que habilitaram uma nova roupagem urbana, alocada pelos novos apêndices econômicos, produtivos e sociais em Sobral, via conjugação de políticas publicas e interesses capitais particulares em décadas passadas, vêm-se assistindo nesse tramitar e sobre esta cidade sertaneja cearense, a promoção de uma Rede Urbana na parte norte do estado, elencando e conjugando nesta perspectiva um "conjunto de centros urbanos, funcionalmente articulados entre si" (CORRÊA, 2010, p. 94).

Neste processar, a palavra chave é articulação. Esta é mediada por vários instrumentos, condições e sujeitos que em conjunto ou de forma isolada, a partir de suas ações contribuem para a dinamização da tessitura urbana, resultando em formas e conteúdos diferenciados. Estes fazem da cidade de Sobral, um espaço urbano que se conecta/articula de forma cada vez mais espacializada com outros centros. Essa condição reúne motivos para uma compreensão mais apurada de que cidade do sertão do Ceará vem se remodelando, reafirmando seu papel regional de comando e contribuindo nesse ínterim para a confecção de uma rede urbana que se revela cada vez mais promissora para investimentos e a promoção de um novo sentido de viver nos sertões.

Este novo sentido é ampliado quando da reformulação das condições imagéticas negativas que historicamente foram condicionadas aos espaços secos do Nordeste brasileiro. Mas, dada as projeções das políticas e alianças aqui narradas e decorrentes dos fatos destacados, as referidas condições vem sendo permitidas a partir de diferentes ações de marketing político e empresarial, onde cidades como 
esta em discussão, são vendidas como tentativa à sua inserção no mercado competitivo e convidativo a investimentos, dando destaques aos novos sentidos do "consumo, os modos de vida e as formas de apropriação do espaço, mediadas por novas formas de exercício do poder e pelas estratégias atualizadas das políticas urbanas" (SÁNCHEZ, 2003, p. 16).

As novas formas de exercício de poder, entre outras possibilidades, dão-se pela presença e qualidade dos diversos equipamentos urbanos na cidade e que foram renovadas como resultado da conjugação de ações político/empresariais em modernizar a cidade. Ao lado destes, soma-se também a presença dos equipamentos comerciais e de consumo capital. Assim, estes, revelam-se como além de essenciais, também estratégicos, uma vez que ajudam a manter a continuidade de vida e ciranda de desenvolvimento fora da capital do estado, de modo que seu alcance não é a apenas local, mas regional.

Assim, as formas e condições de renovação socioespacial em Sobral já discutidas vem revelando não apenas um conjunto de novos conteúdos, mas também de mudança de hábitos de consumo e comportamentos sociais por parte de sua sociedade em processo de transformação, típicos das grandes cidades. Este fato realça a composição de uma nova condição social na cidade, marcada e influenciada pela crescente e contraditória prática consumista que apesar das dialéticas, vem aproximando o caboclo da roça, com os grandes comerciantes e empreendedores comerciais urbanos; estabelece novos laços entre o universo campestre atrasado, porém produtor e o mundo da cidade em voga e integrando não só territorial, mas social e culturalmente os indivíduos que são influenciados pela cidade de comando regional do sertão cearense.

\section{Referências}

AGUIAR JR., Paulo. A cidade e o rio: produção do espaço urbano em Sobral - Ceará. Dissertação de Mestrado. Programa de Pós Graduação em Desenvolvimento e Meio Ambiente, Universidade Federal do Ceará. Fortaleza, 2005.
ALMEIDA, Humberto Marinho de. Práticas espaciais, gestão seletiva e o desenvolvimento territorial no Ceará. In: XV CISO - Encontro Norte e Nordeste de Ciências Sociais Pré-ALAS Brasil, 2012, Teresina - PI. XV CISO - Encontro Norte e Nordeste de Ciências Sociais Pré-ALAS Brasil, 2012. v. único.

AMORA, Z. B., COSTA, M. C. L. Olhando o mar do sertão: a lógica das cidades médias no Ceará. In: SPOSITO, M. E. B. Cidades médias: espaços em transição (org.) São Paulo: Expressão Popular, 2007.

ARAUJO, Nancy Gonçalves de. A industrialização no Ceará: breves considerações. Instituto de Estudos Sócioambientais. Boletim Goiano de Geografia. 2ed.Goiânia: UFG, 2007, v. 27, p. 97-114.

CARLOS, A. F. A.; DAMIANI, A. L.; SEABRA, O. C. L. (orgs.). O espaço no fim de século: a nova raridade. São Paulo: Editora Contexto, 1999.

COELHO, Modesto Siebra. Sobral, Ceará. In: SILVA, José Borzacchiello; CAVALCANTE, Tércia Correia; DANTAS, Eustógio Wanderlei Correia (Org.). Ceará: um novo Olhar Geográfico. Fortaleza: Edições Demócrito Rocha, 2007. p. 301-337.

CORRÊA, Roberto. Lobato. Trajetórias geográficas. Rio de Janeiro: Bertrand Brasil, 2010.

FREIRE, Heronilson Pinto. O uso do território de Sobral, Ceará pelas instituições de ensino superior. Dissertação de Mestrado. Programa de Pós Graduação em Geografia, Universidade Estadual do Ceará. Fortaleza, 2011.

HOLANDA, Virginia Célia Cavalcante de. Modernizações e espaços seletivos no Nordeste brasileiro. Sobral: Conexão Lugar/Mundo. Tese de Doutorado. Programa de Pós Graduação em Geografia Humana, Universidade de São Paulo. São Paulo, 2007.

Sobral - CE: de cidade do sertão às dinâmicas territoriais da cidade média do presente. In: H. Virginia. C.H; A. Zenilde. B,. (Org.). Leituras e Saberes Sobre o Urbano: cidades do Ceará e Mossoró no Rio Grande do Norte. $1^{\circ}$ ed. Fortaleza: Expressão Gráfica e Editora, 2010, v., p. 75-94.

LIMA, Ernane. Cortez. A Serra da Meruoca. Revista da Casa da Geografia, Sobral, 1999. p. 45-49.

LIMA, Juscelino Gomes. Espaços construídos, imagens fragmentadas - Condições da paisagem urbana à imagem turística e ambiental da "Fortaleza Bela". Trabalho de Conclusão de Curso. Pós Graduação em Turismo e Meio Ambiente. Universidade Estadual do Ceará - UECE, 2011. 90 f.

MELLO-THÉRY, Neli Aparecida de. POLÍTICA (E AÇÃO) PÚBLICA, TERRITÓRIO E O PAPEL DA GEOGRAFIA. Revista da ANPEGE, v. 7, p. 11-19, 2011. 
RODRIGUES, A. H. V.; HOLANDA, VC.C. As feições da especulação imobiliária e a produção do espaço da cidade média de Sobral-CE. Revista da Casa de Geografia de Sobral, v. 14, p. 44-55, 2012.

SÁNCHEZ, Fernanda. A reinvenção das cidades para um mercado mundial. Chapecó-SC: Argos Editora Universitária, 2003.

SANTOS, Milton. Pensando o Espaço do Homem. São Paulo: Hucitec, 1982.

Técnica, espaço, tempo: globalização e meio técnico-científico informacional. São Paulo: HUCITEC, 1994.

Espaço do cidadão. São Paulo: Nobel, 1996.

Por uma outra Globalização: do pensamento único à consciência universal. Rio de Janeiro: Record, 2000.

.; SOUZA, Maria Adélia A. de; SILVEIRA, Maria Laura (Org.). Território: globalização e fragmentação. São Paulo: Hucitec, 2006.

SOUZA, Maria Salete. Ceará: bases de fixação do povoamento e o crescimento das cidades. In: SILVA, José Borzacchiello; CAVALCANTE, Tércia Correia; DANTAS, Eustógio Wanderlei Correia (Org.). Ceará: um novo Olhar Geográfico. Fortaleza: Edições Demócrito Rocha, 2007. p. 13-31.

SPOSITO, Maria Encarnação Beltrão. Para pensar as pequenas e médias cidades brasileiras. Belém: FASE/ICSA/UFPA, 2009. v. 1.

STAMM, C.; WADI, Y. M.; STADUTO, J. A. R..São as cidades médias responsáveis pelo espraiamento espacial da riqueza nacional?.Revista REDES (Santa Cruz do Sul. Impresso), v. 15, p. 66-91, 2010. 